\title{
GROUND-PENETRATING RADAR INVESTIGATION OF A RAPIDLY DEVELOPED SMALL ISLAND IN A LAKE IN SOUTHERN GEORGIA, USA
}

\author{
Can Denizman ${ }^{1}$, Eric C. Brevik²*, and Jim Doolittle ${ }^{3}$
}

\begin{abstract}
Collapse sinkholes commonly form in karstic limestones of the Floridan aquifer of southern Georgia, USA. The limestones are capped by impermeable strata that can obscure developing sub-surface voids and catastrophically collapse when too much of their underlying support has been removed. We investigated the overnight appearance of an island in a Georgian lake and its possible relationship to the underlying Floridan aquifer using ground-penetrating radar and global-positioning-satellite spot elevations. The island is adjacent to a submerged sinkhole with an arcuate depression and whose development included convergent downward slumping. Compression created by the convergence probably squeezed lake-bottom sediments upward to form the unusual island. Our methodology can be applied to other lakes in karst regions and may prove useful for diagnosing existing or future subsidence risks.
\end{abstract}

\section{INTRODUCTION}

On the morning of October 13, 2006, residents of a small private lake in southern Georgia near the city of Valdosta woke up to discover a new addition to their lake: a small, newly emergent island. Figure 1 shows the mass of earthen materials that emerged from the lake bottom and formed this strange phenomenon. The lake's residents wanted to know what had led to the formation of this island and what it might mean for the future of their lake.

\section{Geologic Setting}

The Valdosta region in southern Georgia is characterized by karst. Karst in southern Georgia and Florida has developed in a relatively stable tectonic setting and is covered by either thick, impermeable siliciclastics or thin layers of Pleistocene deposits. Unlike tectonically deformed, uplifted, bare karst of many temperate regions such as the Mediterranean, where almost all the drainage takes place underground, or tropical karst with positive features surrounded by doline fields, the karst in southern Georgia displays a gently rolling topography with few, widely spaced, usually shallow depressions. However, this gentle topographic relief and relatively low depression density represent a muted surficial expression of a much denser doline network that is covered by at least several meters of soil material or as much as hundreds of meters of impermeable confining layers (Huddlestun, 1997; Denizman, 1998).

Sinkholes (dolines) are the signature landform in the temperate karst of southern Georgia and Florida. Karst development is active, and modern sinkhole formation is reported frequently, especially during prolonged drought conditions or after heavy rainfall. In some cases, accumulation of low-permeability material within depressions restricts the infiltration of water and results in the formation of ponds and lakes. These materials and processes may retard sinkhole development. Many of the lakes in Florida and southern Georgia occupy basins formed within karstic depressions lined by impermeable material.

Kindinger et al. (1999) describe lake development in sinkhole basins as occurring due to one of two processes, dissolution of underlying limestone or the collapse, subsidence, or slumping of overburden. They then divide the lakes into four geomorphic types based on progressive developmental phases: active, transitional, mature, and polje. Formation of sinkhole-related lakes is controlled by the extent of karst development in the host limestone rock and by the thickness of the overburden or confining unit. Initially, a collapse sinkhole may be open or water-filled depending on the potentiometric level. Later, the sinkhole may be plugged by sediments that have washed into the depression. This process continues until the sinkhole is buried.

\section{Hydrogeologic Setting}

The Floridan aquifer, one of the most productive karst aquifers of the world, is the principal aquifer in southern Georgia. It consists of a thick sequence of Tertiary carbonate rocks. Because of the relatively high primary porosity coupled with extensive karstic dissolution conduits within the carbonate rocks of the Floridan aquifer, groundwater storage and flow take place through a complex system of intergranular openings and cavities.

\footnotetext{
Disclaimer: Trade names or commercial products are given solely for the purpose of providing information on the exact equipment used in this study and do not imply recommendation or endorsement by Valdosta State University, Dickinson State University, or the USDA.

* corresponding author

${ }^{1}$ Department of Physics, Astronomy, and Geosciences, Valdosta State University, Valdosta, GA 31698, cdenizma@valdosta.edu

${ }^{2}$ Departments of Natural Sciences and Agriculture and Technical Studies, Dickinson State University, Dickinson, ND 58601, Eric.Brevik@dsu.nodak.edu

${ }^{3}$ USDA-NRCS-NSSC, 11 Campus Boulevard, Suite 200, Newtown Square, PA 19073,jim.doolittle@lin.usda.gov
} 


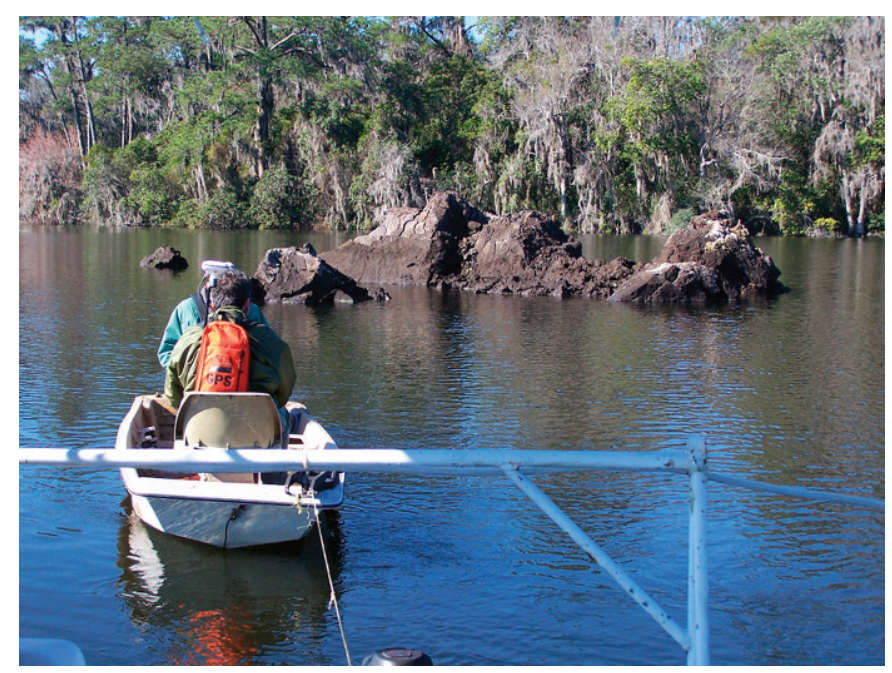

Figure 1. The island seen in this photograph emerged overnight from a southern Georgia lake on October 13, 2006. The boat in the foreground gives a scale for the abovewater size of the feature. All of the materials observed in the emergent island were unconsolidated.

Both diffuse and conduit groundwater flows occur. Most of the cave systems that facilitate conduit groundwater flow are reported to have formed at the contact between the Floridan aquifer and the overlying confining units of the Hawthorn Group (Denizman, 1998).

The siliciclastic rocks of the Hawthorn Group, along with the younger overlying, unconsolidated, impermeable units, create confined conditions throughout much of the area. However, there are numerous places where the confining units are breached by sinkholes. Recharge to the Floridan aquifer is provided by slow leakage through the confining units or by point recharge through collapse depressions that breach the overlying confining unit.

\section{Use of GPR in Karst Settings and LAKes}

Ground-penetrating radar (GPR) measures the time it takes for a shortwave electromagnetic pulse to travel from a radar antenna to a subsurface interface and back to the antenna after being reflected off the interface. The greater the contrast in the electrical properties of the materials at the interface, the stronger the reflected pulses will be. Highconductivity materials lead to greater attenuation of radar energy than low-conductivity materials, and therefore, higher conductivity materials lead to shallower effective exploration depths with GPR. Typical effective exploration depths are a few meters, but can be greater than 30 meters if the geologic setting is favorable (i.e., sediments with primarily low conductivity such as dry sands) (Barr, 1993).

GPR tends to work well in southern Georgia because the surficial sediments are principally sands (Truman et al, 1994), which have a low conductivity (Barr, 1993). These sands may overlie clays, which have a higher conductivity than sands, or limestone, which has a similar or lower conductivity than sands (Barr, 1993). In general, the conductivity of these earthen materials is not high enough to cause significant attenuation of the radar energy and restrict penetration depths.

In southern Georgia, contrasting layers of sands, clays, and limestone are often separated by abrupt boundaries or interfaces. The amount of energy that is reflected back to a radar antenna by an interface is dependent upon the contrast in the relative dielectric permittivity $\left(E_{r}\right)$ of the two layers. Abrupt boundaries that separate contrasting materials reflect more energy than gradual boundaries that separate materials with similar $E_{r}$. The $E_{r}$ of soil materials is principally dependent upon moisture content (Annan et al., 1991) and varies with temperature (phase-dependent), density, and antenna frequency (Daniels, 2004).

Because of these favorable electromagnetic properties, GPR has been used extensively in southern Georgia and Florida to map soil features, such as depth and spatial variability of argillic horizons and depth to parent material, water features, such as wetting fronts and water table depths (Truman et al., 1994; Barr, 1993), and geologic features, such as sediment thicknesses, depths to clay beds, and subsurface karst development (Kruse et al., 2006; Wilson, 1995; Collins et al., 1994; Barr, 1993).

GPR has also been used to investigate lakes and reservoirs. Truman et al. (1991) used GPR to map the depth of a reservoir in west-central Georgia, relying on differences in the relative dielectric permittivity of water versus lake-bottom sediments to provide strong and easily recognized reflections. When compared to control measurements, water depths interpreted from radar records showed a strong linear relationship with an $R^{2}$ value of 0.989. Barr (1993) used GPR to investigate the hydrogeology of freshwater lakes in Florida, including disturbance of lake-bottom sediments. Other examples of the use of GPR to map freshwater bottom topography and sediments include Buynevich and Fitzgerald (2003), Moorman (2001), Moorman and Michel (1997), Mellett (1995), Sellmann et al. (1992), Izbicki and Parker (1991), Kovacs (1991), and Haeni et al. (1987).

Because southern Georgia is in an active karst zone with fairly shallow limestone bedrock under primarily marine deposits, a karst explanation was deemed most likely in the case of this mysterious island. The past successes using GPR to investigate karst features in the southeastern United States and in freshwater bodies led to the use of GPR as the primary means of investigating this particular unusual geologic occurrence.

\section{Materials And Methods}

\section{Survey Equipment and Procedures}

The radar unit used was the TerraSIRch Subsurface Interface Radar System-3000, manufactured by Geophysical Survey Systems, Inc. of Salem, New Hampshire (GSSI). The SIR System-3000 weighs about $4.1 \mathrm{~kg}$ and is 
backpack-portable. A $70-\mathrm{MHz}$ antenna was used in this survey. Within the study lake, the $70-\mathrm{MHz}$ antenna provided adequate depth (greater than $10 \mathrm{~m}$ ) and acceptable resolution of subsurface features.

Radar records contained in this report were processed with the RADAN for Windows version 5.0 software program developed by GSSI. Processing included setting the initial pulse to time zero, color transformation, header and marker editing, distance normalization, horizontal stacking, migration, filtration, and range gain adjustments (Daniels, 2004).

An Allegro CE field computer (Juniper Systems, North Logan, Utah) and a Garmin Global Positioning System Map 76 receiver (with a CSI Radio Beacon receiver, antenna, and accessories that are fitted into a backpack) (Garmin International, Inc., Olathe, Kansas) were used to record the coordinates of each reference station that was impressed on the radar record. SURFER 8.0 (Golden Software Inc., Golden, Colorado) was used to construct the images of the estimated depths to bottom sediments displayed in this paper.

The radar system and $70-\mathrm{MHz}$ antenna were mounted in a fiberglass boat that was towed behind a pontoon boat. GPR surveys were restricted to the portion of the lake near the island. The island was closely approached, but emerged areas were not surveyed. The boats made eleven traverses across the area, each of different lengths. Locations of traverse lines were arbitrary and were adjusted using identifiable features on the shore and island. Reference points for both GPS and GPR were recorded simultaneously at intervals of 30 seconds.

\section{Calibration of GPR}

Ground-penetrating radar is a time-scaled system. This system measures the time that it takes electromagnetic energy to travel from an antenna to an interface (e.g., soil horizon, top of bedrock, stratigraphic layer) and back. To convert the travel time into a depth scale, either the velocity of pulse propagation or the depth to a reflector must be known. The relationships among depth $(D)$, two-way pulse travel time $(T)$, and velocity of propagation $(v)$ are described in the equation (Daniels, 2004)

$$
v=\frac{2 D}{T} \text {. }
$$

The velocity of propagation is principally affected by the $E_{r}$ of the profiled material(s) according to the equation

$$
E_{r}=\left(\frac{C}{v}\right)^{2}
$$

where $C$ is the speed of light in vacuum. For water, the $E_{r}$ is 80 and the $v$ is $0.033 \mathrm{~m} \mathrm{~ns}^{-1}$. These parameters were used to scale the thickness of the water column or the depth to bottom sediments on the radar records.
With the $70-\mathrm{MHz}$ antenna the lake-bottom sediments were penetrated. Variations in sediments are distinguishable on radar records. However, the compositions and dielectric properties of these layers are unknown. As no borings were made through these sediments, the identity of these layers cannot be verified, nor can their thicknesses be accurately estimated. A constant-depth scale has been used on the accompanying radar records. This scale is based on the dielectric permittivity (80) and pulse propagation velocity $\left(0.033 \mathrm{~m} \mathrm{~ns}^{-1}\right)$ of fresh water. While the thickness of the water column is accurately portrayed in the accompanying radar records, the scale is inaccurate within the bottom sediments and underlying layers, which, because of lower water contents, should have lower dielectric permittivities and faster pulse propagation velocities.

\section{InVESTigation OF IsLAND SEDIMENTS}

Eight samples of known volume were collected from the island, and a core was collected to a depth of about $1.5 \mathrm{~m}$. The samples of known volume were analyzed for bulk density by drying the samples for 24 hours at $105{ }^{\circ} \mathrm{C}$. Organic-matter content was determined for these samples using the loss-on-ignition method at $550{ }^{\circ} \mathrm{C}$ (Heiri et al., 2001; Dean, 1974). These measurements were done for comparison to other local lake-bottom sediments studied by Leandro et al. (2005).

\section{RESULTS}

Radar records were of excellent interpretive quality. Figure 2 is a portion of the radar record from traverse line 6 (see Figure 4 for location). The emergent island was approached closely along this transverse, but was not crossed. This traverse line crosses the impacted area in an east-northeast to west-southwest direction. Although the radar provides a continuous profile of the lake, measurements of the water depth were restricted to reference points (numbered white, vertical lines at the top of the radar record). These lines were impressed on the radar record by the operator at a time interval of about 30 seconds. In Figure 2, the emergent island is most closely approached between reference marks 5 and 6 .

In Figure 2, the horizontal, high-amplitude (colored white and grey) reflector at the top of the radar record represents the reflection from the lake's surface. Below the surface reflection, the first series of high-amplitude reflections represents the lake bottom (see point A). On this portion of the radar record, this interface varies in depth from about 1.78 to $7.64 \mathrm{~m}$. Between horizontal reference marks 5 and 6 , reflections from this interface are noticeably mixed, lower in signal amplitude (colored red, yellow, and blue), segmented, and dipping towards the northeast and away from a deep sinkhole that is evident between reference marks 6 to 8 . Lines have been 


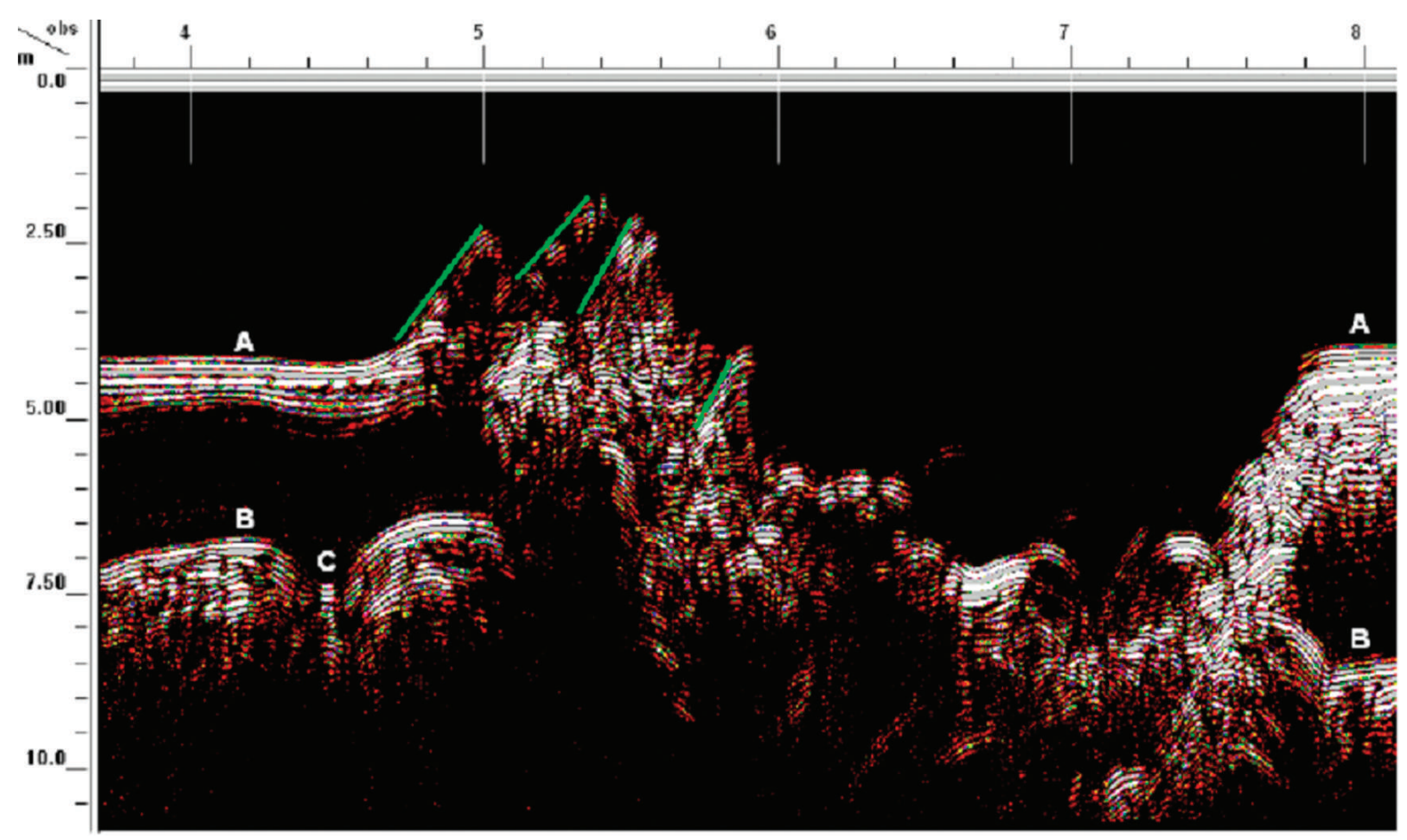

Figure 2. A deep sinkhole and shoved, elevated lake-floor sediments are evident in this portion of the GPR record from traverse line 6. This traverse line crosses the study area in an east-northeast (left side) to west-southwest (right side) direction. $A$ sinkhole can be seen roughly between reference marks 6 and 8 . The lake bottom is shown by reflections at point $A$, the reflection at point $B$ is suspected to represent the top of the local limestone bedrock. A small depression in the surface is indicated at point $\mathbf{C}$.

drawn between reference marks 5 and 6 to draw attention to the downward-dipping reflections from layers of former sub-bottom sediments that have been moved upwards along the eastern rim of the sinkhole. A sharp drop-off is evident near reference mark 8. Here, downward-bending bands of reflectors suggest the collapse of sediments into the sinkhole. Though not verified, it is suspected that the high-amplitude planar reflector at point B represents the upper boundary of the underlying limestone bedrock. If so, a potential cavity in this surface is suggested at point C. The black zone between the depths of about $5 \mathrm{~m}$ and $7 \mathrm{~m}$ most likely represents fairly uniform lake bottom materials.

Figure 3 is a portion of the radar record from traverse line 11 (see Fig. 4 for location). This traverse line crosses to the west of the emergent island and across the sinkhole from north-northwest to south-southeast. This traverse line is essentially orthogonal to traverse line 6 (shown in Fig. 2). In Figure 3, the emergent island is most closely approached between reference marks 6 and 8 . The horizontal, high-amplitude reflector at the top of the radar record represents the reflection from the lake's surface. Below the surface reflection, the first series of highamplitude reflections represents the lake bottom (see point A). On this portion of the radar record, this interface is essentially horizontal on either side of the sinkhole, but is slightly lower (about 4.05 to $4.10 \mathrm{~m}$ below the lake surface) on the left-side (north-northwest) and slightly higher (about $3.9 \mathrm{~m}$ below the lake surface) on the right-side (south-southeast). Two conspicuous, high-amplitude, planar subsurface reflectors (see points B and C) separate distinct sub-bottom sedimentary or lithologic facies. Methods of GPR facies analysis are described for unconsolidated sediments by Beres and Haeni (1991). The reflections near the 10-m depth mark along the left side (north-northwest) likely represent limestone bedrock, but this was not confirmed.

Downward-bending bands of reflectors suggest local rotations and slump folding during the collapse of sediments into the sinkhole on its south-southeastern (right-hand) side (Fig. 3). On the north-northwestern (left-hand) side of the sinkhole, near reference mark 4, down-turned bands of reflectors are less evident, and the abrupt truncation of reflectors suggests a much sharper break. Both sides of the sinkhole show layer slumping, with dips toward the center of the sinkhole.

The depths to bottom sediments were calculated using GPR at 169 points, and GPS was used determine locations for the points. The average depth to bottom sediments within the survey area is $3.96 \mathrm{~m}$ with a range of $1.09 \mathrm{~m}$ to $6.96 \mathrm{~m}$. At one half of the reference points, depths to bottom sediments were between $3.77 \mathrm{~m}$ and $4.21 \mathrm{~m}$. While these statistics are useful, a two-dimensional plot of these depth estimates would provide a more coherent picture of 


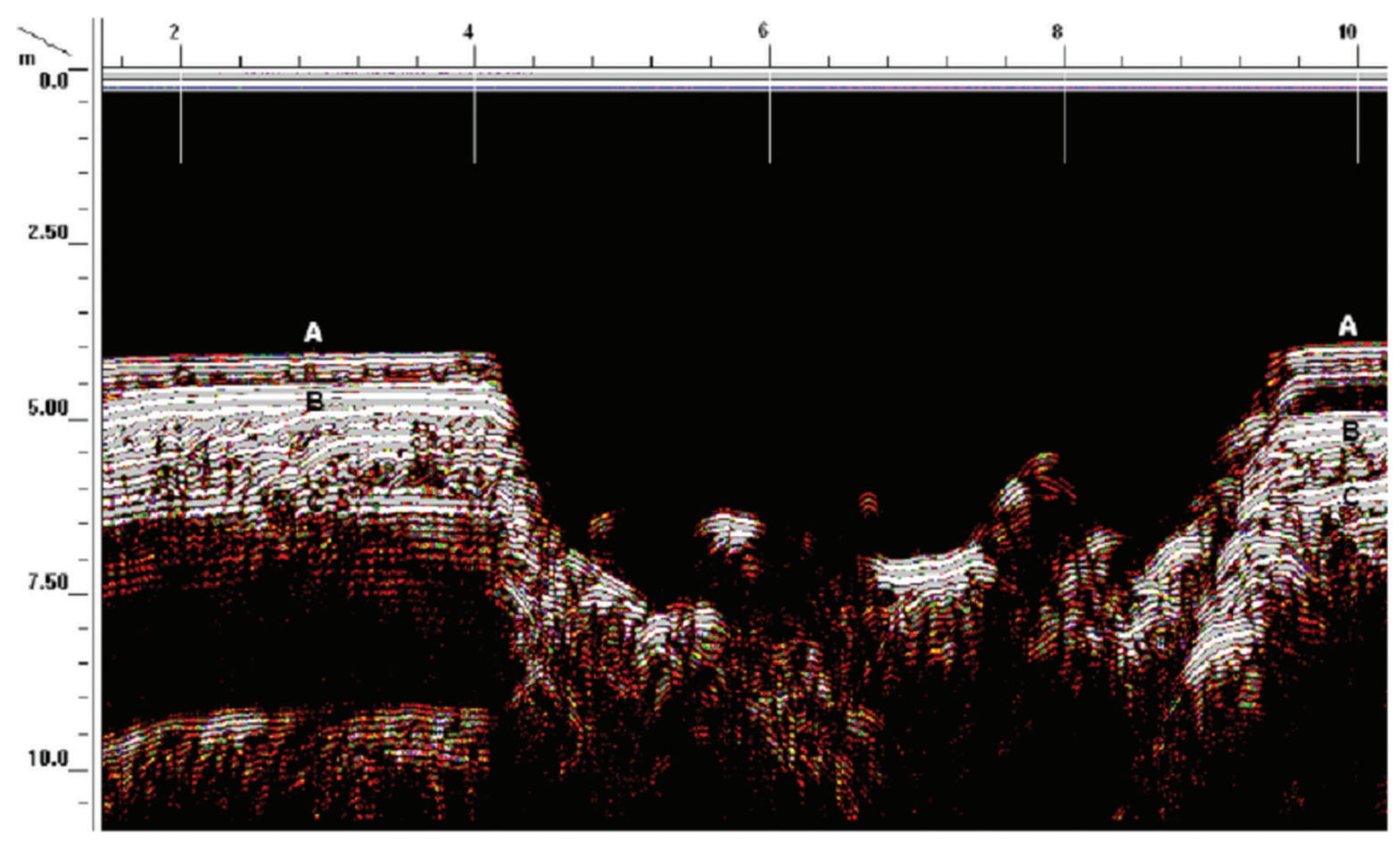

Figure 3. A portion of the radar record from traverse line 11 showing the crater-like feature and collapsed lake-floor sediments. This traverse line crosses to the west of the emergent island and across the crater-like feature from north-northwest to southsoutheast. A sinkhole can be seen roughly between reference marks 4 and 10. The lake bottom is shown by reflections at point $A$. The reflections at points $B$ and $C$ represent separate distinct, sub-bottom sedimentary and/or lithologic facies. The top of the suspected limestone bedrock is shown at a depth of approximately 8-9 $\mathrm{m}$ on the left side of the figure.

the emergent island area. Figure 4 shows a two-dimensional contour map of the lake bottom with a contour interval of $50 \mathrm{~cm}$. Portions of the island that emerge from the lake are labeled A. It must be emphasized that data used to prepare Figure 4 were collected only in areas that the boats could reach. No measurements were collected on the emergent island because the sediments were too soft to allow surveying, so the elevations of the emergent portions of the island are estimated.

The eight sediment samples collected from the island had a very low bulk density (average $0.20 \mathrm{~g} \mathrm{~cm}^{-3}$, standard deviation $0.08 \mathrm{~g} \mathrm{~cm}^{-3}$ ) and high organic matter content (average 49\%, standard deviation 9.3\%). The core sample had a uniform appearance throughout its length. No lithified materials were noted in the island materials. These results are consistent with the composition and bulk density of lake-bottom sediments from other nearby lakes (Leandro et al., 2005).

\section{Discussion AND CONCLUSION}

Cover-collapse and cover-subsidence sinkholes are common surficial karst features in temperate karst regions with thick overburden material. Most of the ponds and even some large lakes in Florida and south Georgia are formed by sinkhole-related collapse. Many of them develop in response to subsurface karst development and subse- quent collapse of the overburden. However, island formation has never been reported to occur along with these depression processes.

The mysterious island that formed overnight in a Georgia lake is an unusual result of a sinkhole collapse within the highly karstic carbonates underlying the lake bottom. Steep walls of the apparently new sinkhole indicate a sudden collapse of a bedrock cavity around reference mark 8 and upward movement of lake bottom and cavity sediments between reference marks 5 and 6 . We propose this unusual feature is composed of lake sediments that were probably scraped off the lake bottom and squeezed upward as they underwent convergent downward slumping into an apparently arcuate-shaped sinkhole throat. Displaced water may have also played a role. As the collapse occurred, enough sediment and rock may have dropped into the collapse to displace a significant amount of water upward. This displaced water may have then "rafted" the sediments that compose the emergent island upward into an angled position.

Using the classification of Kindinger et al. (1999), this lake would classify as a lake that developed due to the collapse or subsidence of overburden to form a sinkhole. It is most likely in the transitional development phase. Given that the lake is already present, it is too advanced to be in the active phase, but the creation of the island indicates that karstification is still active in this system. 


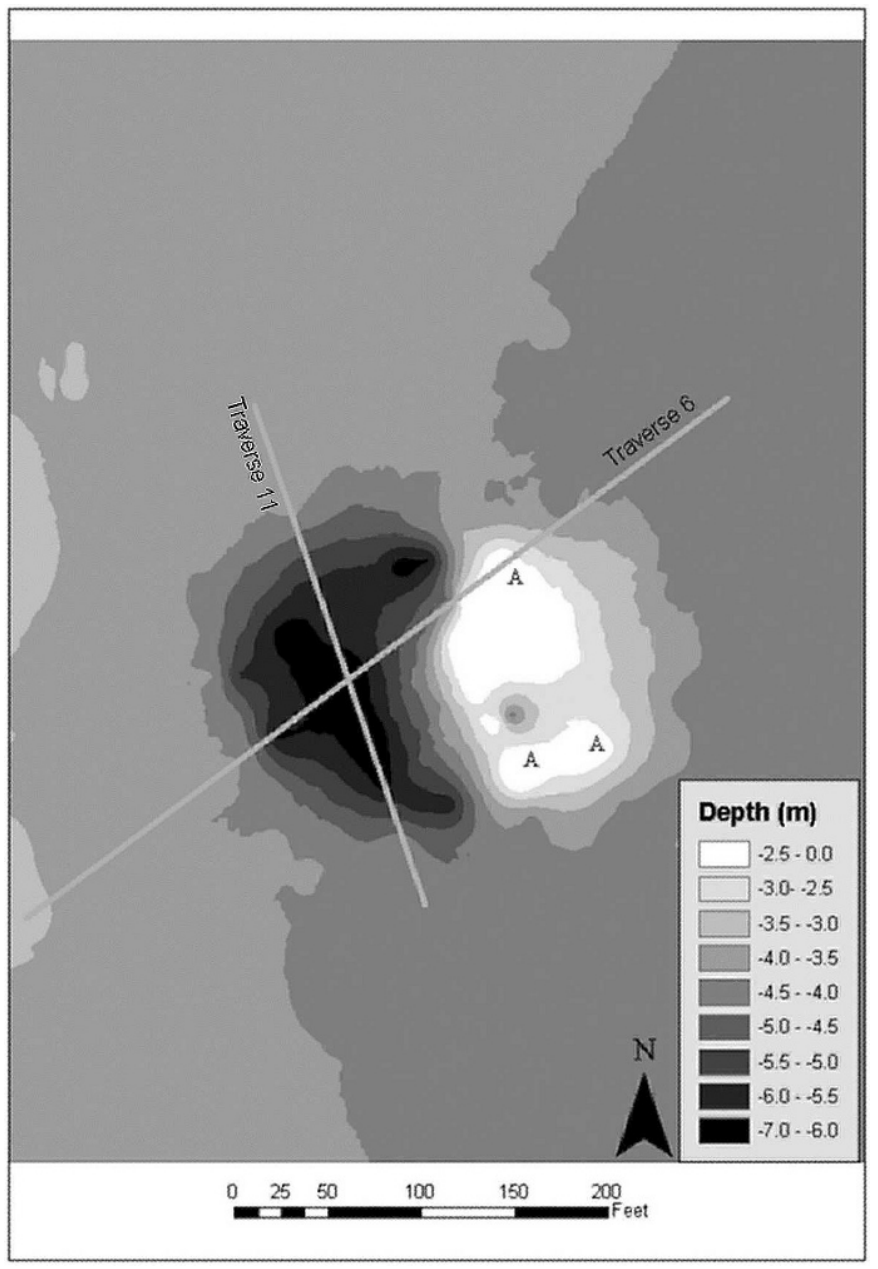

Figure 4. The locations of emergent land are denoted by the letter $\mathbf{A}$ in this two-dimensional contour map of the lakebottom depths in the study area. The locations of the segments of the radar records shown in Figures 2 (Traverse 6) and 3 (Traverse 11) are also indicated.

\section{REFERENCES}

Annan, A.P., Cosway, S.W., and Redman, J.D., 1991, Water table detection with ground penetrating radar: Tulsa, Oklahoma, Society of Exploration Geophysicists, Expanded Abstracts $61^{\text {st }}$ Annual Meeting, v. 1, p. $494-495$.

Barr, G.L., 1993, Application of ground-penetrating radar methods in determining hydrogeologic conditions in a karst area, west-central Florida: U.S. Geological Survey Water-Resources Investigations Report 92-4141, 26 p.

Beres, M., and Haeni, F.P., 1991, Application of ground-penetrating radar methods in hydrogeologic studies: Ground Water, v. 29, p. 375-386.

Buynevich, I.V., and Fitzgerald, D.M., 2003, High-resolution subsurface (GPR) imaging and sedimentology of coastal ponds, Maine, USA: implications for Holocene back-barrier evolution: Journal of Sedimentary Research, v. 73 , no. 4 , p. 559-571.
Collins, M.E., Cum, M., and Hanninen, P., 1994, Using groundpenetrating radar to investigate a subsurface karst landscape in north-central Florida: Geoderma, v. 61, p. 1-15.

Daniels, D.J., 2004, Ground penetrating radar, 2nd edition, London, The Institute of Electrical Engineers, $760 \mathrm{p}$.

Dean, W.E., 1974, Determination of carbonate and organic matter in calcareous sediments and sedimentary rocks by loss on ignition: comparison with other methods: Journal of Sedimentary Petrology, v. 44 , no. 1 , p. $242-248$.

Denizman, C., 1998, Evolution of karst in the lower Suwannee River basin, Florida [Ph.D. thesis]: Gainesville, Fla., University of Florida, 214 p.

Haeni, F.P., McKeegan, D.K., and Capron, D.R., 1987, Groundpenetrating radar study of the thickness and extent of sediments beneath Silver Lake, Berlin and Meriden, Connecticut: US Geological Survey Water-Resources Investigation Report 85-4108, 19 p.

Heiri, O., Lotter, A.F., and Lemcke, G., 2001, Loss on ignition as a method for estimating organic and carbonate content in sediments: reproducibility and comparability of results: Journal of Paleolimnology, v. 25, p. 101-110.

Huddlestun, P.F., 1997, Geologic atlas of the Valdosta area: Atlanta, Georgia Geologic Survey Geologic Atlas 10, 27 p.

Izbicki, J.A., and Parker, G.W., 1991, Water depth and thickness of sediment in reservoirs 1 and 2, Framingham and Ashland, Massachusetts: US Geological Survey Open-File Report 91-508, 18 p.

Kindinger, J.L., Davis, J.B., and Flocks, J.G., 1999, Geology and evolution of lakes in north-central Florida: Environmental Geology, v. 38 , no. 4 , p. $301-321$

Kovacs, A., 1991, Impulse radar bathymetric profiling in weed-infested fresh water: CRREL Report 91-10, 25 p.

Kruse, S., Grasmueck, M., Weiss, M., and Viggiano, D., 2006, Sinkhole structure imaging in covered karst terrain: Geophysical Research Letters, v. 33, L16405 p.

Leandro, A.M., Wall, A., Hyatt, J.A., and Brevik, E.C., 2005, Identifying spatial trends in the physical properties of sediments, Lake Louise, Georgia [abs.]: Geological Society of America Northeastern Section 40th Annual Meeting, Geological Society of America Abstracts with Programs, v. 37 , no. $1,15 \mathrm{p}$.

Mellett, J.S., 1995, Profiling of ponds and bogs using ground-penetrating radar: Journal of Paleolimnology, v. 14, p. 233-240.

Moorman, B.J., 2001, Ground-penetrating radar applications in paleolimnology, in: Last, W.M., and Smol, J.P., eds., Tracking Environmental Change using Lake Sediments: Physical and Chemical Techniques: Dordrecht, The Netherlands, Kluwer Academic Publishers, p. $1-25$.

Moorman, B.J., and Michel, F.A., 1997, Bathymetric mapping and subbottom profiling through lake ice with ground-penetrating radar: Journal of Paleolimnology, v. 18, p. 61-73.

Sellmann, P.V., Delaney, A.J., and Arcone, S.A., 1992, Sub-bottom surveying in lakes with ground-penetrating radar: CRREL Report 92-8.

Truman, C.C., Asmussen, L.E., and Allison, H.D., 1991, Groundpenetrating radar: a tool for mapping reservoirs and lakes: Journal of Soil and Water Conservation, v. 46, no. 5, p. 370-373.

Truman, C.C., Bosch, D.D., Allison, H.D., and Fletcher, R.G., 1994, Uses of ground-penetrating radar in the Georgia Coastal Plain: review of past and current studies: US Department of Agriculture, Agricultural Research Service. ARS-124. 32 p.

Wilson, W.L., 1995, Sinkhole and buried sinkhole densities and new sinkhole frequencies in karst of northwest peninsular Florida, in: Beck, B.F., ed., Karst Geohazards: Engineering and Environmental Problems in Karst Terrain: Proceedings of the Fifth Multidisciplinary Conference on Sinkholes and the Engineering and Environmental Impacts of Karst, Gatlinburg, Tennessee, April 2-5: Leiden, The Netherlands, A.A. Balkema, p. 79-91. 